\title{
NOTICIAS
}

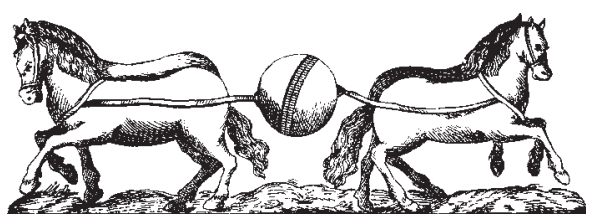

\section{Congreso Internacional sobre Investigación en la Didáctica de las Ciencias}

Enseñanza de las Ciencias celebra su VII Congreso que tendrá lugar en Granada, del 7 al 10 de septiembre de 2005, bajo el lema Educación científica para la ciudadanía. Se organiza en torno a cuatro ámbitos científicos: 1) Enseñanza de las ciencias y sociedad. 2) Proyectos curriculares «en contexto». 3) Relación entre la investigación, la innovación y la práctica. 4) Procesos comunicativos en la enseñanza y difusión de las ciencias.

Información: <blues.uab.es/rev-ens-ciencias/congreso><cg.ensenanza.ciencias@uab.es>

III EPEA: Pesquisa em educaçao ambiental

Fecha y lugar: del 10 al 13 de julio de 2005 en Ribeirão Preto/USP, Brasil.

Información: Tel: 5516 602-3848

<epea3@ffclrp.usp.br>

VII International conference on technology and mathematics teaching (ICTMT7)

Fecha y lugar: del 26 al 29 de Julio de 2005, en Bristol, GB.

Información:

http://www.ictmt7.org/main_reg_form.cfm

\section{Conferencia ESERA}

Fecha y lugar: del 28 de Agosto al 1 de septiembre 2005 en Barcelona, España. Información: Roser Pintó, ESERA
2005, coordinadora.

Tel +34-935813206

Fax: +34-935811169

roser.pinto@uab.es

http://www.ESERA2005-CRESILS.org

XI Encontro nacional de educaçao em ciencias

Fecha y lugar: septiembre de 2005 en Porto, Portugal.

Información:

http://www.enec2005.ese.ipp.pt/

I Congreso internacional sobre la teoría antropológica de lo didáctico. Sociedad, escuela y matemáticas

Fecha y lugar: del 27 al 30 de octubre de 2005, en Baeza, España.

Información:

http://www4.ujaen.es/ aestepa/TAD/
III Congreso de comunicación social de la ciencia

Fecha y lugar: del 9 al 11 de noviembre de 2005, en A Coruña, España.

Información: Secretaría III Congreso sobre Comunicación Social de la Ciencia, Museos Científicos Coruñeses (=mc2),

La Coruña, España.

Tel: +34981 189840

http://www.casaciencias.org/congreso

IV Jornadas internacionales para la enseñanza pre-universitaria de la química

Fecha y lugar: del 15 al 18 de noviembre de 2005, en Mérida, Yucatán, México.

Información: Adela Castillejos Salazar, Directora del Centro Nacional de Educación Química

Tel: 56233069

Fax: 53864832

<adelac@servidor.unam.mx>

http://www.cneq.unam.mx

\section{LIBROS RECIBIDOS}

Pérez Miranda, R., Gallego Badillo, R., Torres de Gallego, L.N. y Hawer Cuéllar fernández, L. (2004). Las competencias interpretar, argumemtar y proponer en Química. Bogotá: Universidad Pedagógica Nacional.

Ruesca Ramos, M.P. (2004). El inicio del razonamiento en la infancia. Burgos: Universidad de Burgos. 